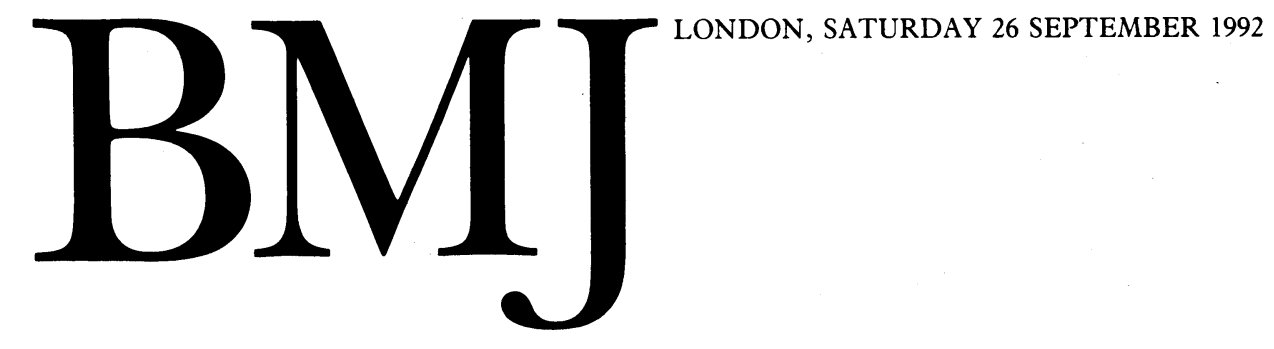

\title{
Rabies in Europe
}

\section{Now possible to confine and eliminate}

Since 1950 the type of rabies that has occurred in continental Europe has been maintained essentially in red foxes, in contrast to the type that prevailed at the start of the century, which was maintained in dogs. ${ }^{1}$ This difference in hosts is important. Even though both viruses are of serotype 1, the fox virus is of low infectivity for dogs, and vice versa. When one of these two species becomes infected with the heterologous virus it sheds little virus. Thus the transfer of fox rabies virus from an infected country to a rabies free country in Europe would not readily occur through dogs. ${ }^{1}$

The current strategy for controlling rabies in continental Europe is therefore to protect domestic animals by parenteral vaccination and to reduce the wildlife reservoir of the virus by oral vaccination of foxes (the main effort). ${ }^{2}$ With this strategy terrestrial rabies could soon disappear from Europe (except for Turkey, where rabies is maintained in dogs). Nevertheless, in some countries rabies could still persist in bats and arctic animals. The Arctic fox is a host for another distinct rabies virus, and markers of this virus have been recognised in outbreaks among non-arctic animals, including the red fox, the raccoon dog, domestic dog, and perhaps wolf. ${ }^{3}$ Such outbreaks could maintain an epizootic (an epidemic in animals).

The present red fox rabies epizootic of central Europe is thought to have started in 1939-40 at the Russian-Polish border and advanced mainly westwards stopping in eastern France in about 1982. The factors that influence the epizootic are the density of the fox population, its rate of turnover, and foxes' social behaviour. ${ }^{4}$ Changing numbers of foxes, as rabies decimates the population, account for the cyclic incidence of the disease. In autumn about $70 \%$ of the total population are young foxes, born in the spring of that year. This ensures a pool of susceptible animals for the propagation of infection.

The red fox is responsible for 60 to $80 \%$ of all cases of rabies, and a further $10 \%$ of rabid wild animals share the fox's habitat (for example, deer, badger, and other small mustelids). Of domestic animals farm animals bear the brunt, followed by cats and dogs. Human cases are rare. For example, in Germany (including the former German Democratic Republic), a relatively heavily infected country, only two indigenous cases and one imported case were reported from 1977 to $1990 .^{5}$

Previously, measures to control the infection combined vaccinating domestic animals with reducing the number of host species. Poisoning, trapping, and gassing of foxes, however, met with limited success, and the success of a field trial using oral vaccine therefore marks a milestone in the research into rabies. ${ }^{6}$ The aim of the trial was to immunise enough foxes to interrupt the chain of infection. Chicken heads were used as bait, and the vaccine was an attenuated live virus. A new bait (consisting of fat and fish meal) has since improved the seroconversion rate and facilitated mass production. ${ }^{7}$ At least a dozen European countries have now used oral vaccine to immunise foxes. In Turkey, the single European country where dogs make up most registered cases (and human cases are relatively more common), efforts have been made to supplement parenteral vaccination with oral vaccination so as to reach non-accessible dogs. ${ }^{8}$

The rabies that affects bats in Europe is serotype 4 (compared with serotype 1, responsible for rabies in red foxes dogs, and arctic animals). Cases in European bats have been recorded since 1954; from 1985 to 1991,429 cases were reported from Denmark, the Netherlands, Germany, France, Poland, Czechoslovakia, and Spain. Nearly all cases occurred in the serotine bat. No programme for preventing rabies in bats exists. For patients exposed to rabid bats doctors should follow the usual postexposure guidelines, though all rabies vaccines are produced from serotype 1 strains. ${ }^{9}$

Postexposure treatment depends on the animal and the severity of injury that it causes. After local treatment of the wound one of several different combinations of vaccines or immunoglobulin (or both) may be given. ${ }^{10}$ Vaccines remain the most important method for preventing rabies in humans.

To protect against rabies, a country that is free of rabies must ensure that any animal entering its territory is not carrying the virus. Controlling the entry of free living wild animals is virtually impossible, except in countries with insurmountable natural barriers. Island countries are not at risk-except from migratory bats.

By contrast, the entry of domestic animals can be strictly controlled. Two ways exist of ensuring that such animals are not carrying the rabies virus. The first is to place the animals under observation and isolate them for a period equal to the maximum incubation period of rabies. This period varies from a few weeks to a few years, according to species. By imposing a quarantine period of six months, as does the United Kingdom, the risk of an animal developing rabies after leaving quarantine is extremely low, although not zero.

The second way is to verify that the animals have been immunised against rabies before being imported. This depends on a reliable vaccination certificate, preferably supported by the measurement of rabies antibodies. ${ }^{11}$ Those 
European countries that are free from rabies and are geographically isolated (for example, Scandinavia, the Republic of Ireland, and the United Kingdom) have chosen the first solution; the others make do with the second. In practice, over the past 40 years only very few cases of rabies have occurred in areas declared to be free from rabies, found far from the infected zones. Animals imported from Africa have usually been responsible. Such outbreaks have always been controlled immediately by creating a vaccination barrier (for example as occurred in western France, Spain, or Portugal).

Because of the difficulties in applying quarantine and the desire to harmonise animal health regulations, particularly within the European Community, the current trend is to favour vaccination. This requires guarantees that imported animals have been effectively immunised. For this reason the international organisations, notably the World Health Organisation and the Office International des Epizooties, recommend not only the unfalsifiable identification of individual animals but also the testing for rabies antibodies. In its international animal health code the Office International des Epizooties will propose that a satisfactory antibody titre shall be at least twice the titre capable of protecting all animals against fatal experimental infection. Such a titre shows that the animal is immunocompetent and was protected against infection before importation.

Better knowledge of the epidemiology and immunology of rabies, coupled with better vaccines, antibody assays, and veterinary controls make it possible to confine rabies to certain regions. From such regions rabies can be eliminated step by step by giving oral vaccine to foxes.

W W MULLER

Assistant Director

WHO Collaborating Centre for

Rabies Surveillance and Research,

Tübingen,

Germany

J BLANCOU

Director General

Office International des Epizooties

12 rue de Prony,

75017 Paris,

France

1 Blancou J. Ecology and epidemiology of fox rabies in Europe. Rev Inf Dis 1988; 10 (suppl 4); S606-9.

Wandeler AI. Oral immunization of wildlife. In: Baer GM, ed. The natural history of rabies. Baton Rouge: CRC Press, 1991

3 Report of a WHO/NIV workshop on arctic rabies, Uppsala, Sweden, 24-27 April 1990. Geneva: World Health Organisation Division of Communicable Diseases, 1990.

4 Steck F, Wandeler A. The epidemiology of fox rabies in Europe. Epidemiol Reviews 1980;2:71-96. Rabies Bulletin Europe: Information, Surveillance, Research, 4/90, 11; edited by Schneider LG Müller WW. Tübingen: WHO Collaborating Centre for Rabies Surveillance and Research.

Steck F, Wandeler A, Bichsel P, Capt S, Schneider LG. Oral immunization of foxes against rabies. A field study. Zentralb/Veter inarmed [B] 1982;29:372-96.

Schneider LG, Cox JH, Muller WW, Hohnsbeen K-P. Current oral rabies vaccination in Europe: an interim balance. Rev Inf Dis 1988; (suppl 4);S654-9.

WHO/OIE report on third consultation on oral vaccination of dogs against rabies, Geneva 21-22, fuly 1992, Geneva: World Health Organisation Division of Communicable Diseases, 1992.

9 Muller WW Schneider LG Cox JH Epidemilogy, diagnosis and prophylaxis of bat rabies in Muller WW, Schneider LG, Cox JH. Epidemiology, diagnosis and prophylaxis of bat rabies in Europe caused by Duvenhage viruses. In: Koprowski H, Bögel K, Sureau P, eds. Progress in
rabies control. Kent: Wells Medical, 1989 . WhO Export

Guide for postexposure treatment. WHO Technical Report

11 Aubert MFA. Practical significance of rabies antibodies in cats and dogs. Revue scientifique et technique, Office International des Epizooties 1992;11:735-60

\section{On site medical services at major incidents}

\section{Training still the black spot}

Although major incidents (entailing injury and death) are not new in Britain, they were brought into clearer public focus in the 1970s. The terrorist bomb explosion at the Old Bailey ${ }^{1}$ and the crash at Moorgate tube station ${ }^{2}$ received massive and graphic media coverage, partly because of their proximity to Fleet Street.

These incidents also generated much medical interest. Over 150 casualties converged on the accident and emergency department of St Bartholomew's Hospital within 10 minutes of the explosion at the Old Bailey. The fact that the hospital was not overwhelmed remains something of a bench mark in the management of mass casualties and showed that hospital staff working within a familiar environment invariably triumph over potential chaos. The crash at Moorgate established the medical importance of on site care. The last live victim was not released for some 12 hours after the accidentwithout the use of mobile teams several casualties would have died still trapped.

Making use of these and other experiences, the Department of Health issued a directive formalising arrangements for dealing with major incidents. ${ }^{3}$ Many of the problems these incidents present, however, remain unresolved. Although mobile teams are now accepted, a great gulf persists between the medical skill available on site and in hospital. A major incident is usually a "once in a lifetime" experience for the medical staff-which makes preplanning so important and yet so difficult. Relatively few hospital doctors have any experience of on site work, and expecting adequate performance without adequate training is unrealistic. The emergency services regularly meet and train together; frequently the medical service is missing. This creates problems at a real disaster because unfamiliarity between key staff hampers easy communications.

It would seem sensible, therefore, for the mobile team's site medical officer to meet regularly with his or her counterparts in the emergency services. Unfortunately, it can be taken for granted that if the site medical officer is a named person then when the next disaster occurs he or she will be on annual leave. All key posts for mobile teams should therefore fulfil a role rather than be delegated to specific people. This makes planning extremely difficult, not least because of the constant changes in hospital staff.

Good preparation is essential for on site care. Hospital preplanning can greatly help by introducing staff to the equipment that they will have to use, which should be carefully selected and of manageable quantity. Knowing where to find and how to don the distinctive protective overalls will save valuable time on the day. Personal injury to medical staff at the scene of an accident is common. This takes the form of cuts and abrasions from tangled wreckage and, with the current dangers of HIV infection, gloves and eye protection should be worn. Even these simple measures may produce difficulties with, for example, the setting up of an intravenous infusion if the operator is not familiar with wearing gloves.

Participants need to accept an almost complete reversal of the criteria for medical care in hospital. At an accident the most seriously injured may be of low priority until those casualties who would probably survive with simple measures - such as maintenance of the airway or control of 